\title{
TATA RIAS TARI REJANG KERAMAN DESA KEDIS KECAMATAN BUSUNGBIU KABUPATEN BULELENG
}

\author{
Ni Kadek Windi Juniawati ${ }^{1}$, I Dewa Ayu Made Budhyani ${ }^{2}$, I Gede Sudirtha ${ }^{3}$ \\ ${ }^{123}$ Jurusan Pendidikan Kesejahteraan Keluarga \\ Universitas Pendidikan Ganesha \\ Singaraja, Indonesia \\ e-mail: windi.kadek@yahoo.com,made.budhyani@undiksha.ac.id, \\ gede.sudirtha@undiksha.ac.id
}

\begin{abstract}
Abstrak
Penelitian ini bertujuan untuk mendeskripsikan tata rias tari Rejang Keraman pada era modernisasi dilihat dari segi : (1) alat dan jenis kosmetika (2) tata rias wajah dan rambut (3) penataan busana dan aksesoris. Penelitian ini dilaksanakan di Desa Kedis Kecamatan Busungbiu, Kabupaten Buleleng. Jenis penelitian yang digunakan adalah penelitian deskriptif. Metode pengumpulan data yang digunakan adalah metode observasi dan wawancara. Instrumen penelitian ini adalah lembar observasi dan lembar wawancara. Analisis data menggunakan teknik analisis deskriptif. Hasil Penelitian ini adalah : (1) alat yang digunakan pada tata rias tari Rejang Keraman putra dan putri yaitu macam-macam spons, macam-macam kuas, macam-macam sisir, jepit, karet, harnet. Jenis kosmetik yang digunakan adalah fondation, bedak, eye shadow, blush on, pensil alis, eyeliner, lipstick, mascara, hair spray, untuk putranya tidak menggunakan bulu mata palsu. (2) tata rias wajah dan rambut tari Rejang Keraman yaitu merias wajah dan menata rambut menggunakan jenis kosmetika yang lengkap. (3) penataan busana dan aksesoris tari Rejang Keraman putri yaitu pemakaian kebaya, kamben, angkin prada, selendang, badong, gelang kana, kalung emas, subeng. Untuk putra menggunakan baju kaos polos putih berlengan panjang, celana panjang putih, stiwel, kancut, ampok-ampok, kamben songket, semayut, lamak, awir, angkep pala, badong, gelang kana, kris.
\end{abstract}

Kata Kunci: aksesoris, busana, tata rias, tari Rejang Keraman.

\begin{abstract}
This study aims to describe the makeup of Rejang Keraman dance in the modernization era in terms of: (1) tools and types of cosmetics (2) makeup and hair (3) fashion and accessories. This research was conducted in Kedis Village, Busungbiu District, Buleleng Regency. The type of research used is descriptive research. Data collection methods used are observation and interview methods. The instruments of this research are observation sheets and interview sheets. Data analysis using descriptive analysis techniques. The results of this study are: (1) the tools used in the Rejang dance makeup of the sons and daughters of a variety of sponges, various brushes, various combs, flops, rubber, harnet. The types of cosmetics used are foundation, powder, eye shadow, blush, eyebrow pencil, eyeliner, lipstick, mascara, hair spray, for her son not to use false eyelashes. (2) Rejang Keraman dance face and hair make up, which are makeup and hair styling using a complete type of cosmetics. (3) the arrangement of clothing and accessories for Rejang Keraman dance Putri, namely the use of kebaya, kamben, angkin prada, scarves, badong, kana bracelets, gold necklaces, subeng. For men using plain white shirts with long sleeves, white trousers, stiwel, kancut, ampok-ampok, kamben songket, semayut, lamak, awir, angkep pala, badong, kana bracelets, kris.
\end{abstract}

Keywords: accessories, clothing, makeup, Rejang Keraman dance 


\section{PENDAHULUAN}

Bali adalah wilayah yang sudah terkenal tentang keseniannya. Seni sakral merupakan kesenian yang dipentaskan pada saat pelaksanaan suatu yadnya dan di sesuaikan dengan keperluannya. Setiap pelaksanaan upacara Agama Hindu di Bali akan dibarengi dengan seni sakral seperti tari-tarian, antara upacara dengan tarian tidak dapat dipisahkan hampir setiap ada upacara agama pasti dibarengi dengan tari-tarian dengan kata lain dalam upacara agama tanpa ada pertunjukan kesenian khususnya tari Bali rasanya kurang sempurna dan bagi masyarakat Bali terutama pemeluk agama Hindu menganggap tarian mempunyai nilai religius di dalamnya (Yudabakti, 2007:26).

Tari adalah ekspresi jiwa manusia melalui gerak-gerak ritmis yang indah. Gerakan pada seni tari diiringi dengan musik untuk mengatur gerakan penari dan menyampaikan pesan yang dimaksud. Seni tari dibagi menjadi tiga, yaitu: Tari Wali, Tari Bebali, dan Tari Bali-balihan. Tari Wali adalah suatu tari yang pementasannya dilakukan sejalan dengan pelaksanaan upacara agama. Tarian ini tidak mengandung cerita, hanya mengandung simbolis religious, seperti terlukis dalam tarian rejang, pendet, sanghyang, tari baris gede. Tari Bebali adalah tari yang pementasannya menunjang jalannya upacara yakni sebagai sarana pengiring. Tarian ini dipentaskan bersama dengan upacara yang diselenggarakan saat itu, contohnya seperti tari topeng, drama tari, dan yang lainnya. Sedangkan Tari Bali-balihan adalah tari yang tidak termasuk sakral, hanya berfungsi sebagai hiburan dan tontonan yang mempunyai unsur dasar seni tari yang luhur, seperti: Tari Legong, Joged, dan lain-lainnya (Yudabakti, 2007:67).

Tata rias merupakan suatu seni menghias wajah yang bertujuan untuk memperindah dan mempercantik penampilan wajah. Tata rias wajah dengan teknik make-up yang benar akan dapat menutupi beberapa kekurangan yang ada pada wajah dan membuat penampilan wajah akan terlihat fresh.
Secara umum tata rias wajah dibagi menjadi dua yaitu riasan dasar dan riasan dekoratif. Riasan dasar berfungsi sebagai make-up dasar yang dapat dilengkapi dan disempurnakan dengan riasan dekoratif. Pada riasan dasar dapat diaplikasikan kosmetika yang meliputi pemakaian pelembab, alas bedak dan bedak. Riasan dekoratif dilakukan dengan memberikan beberapa sentuhan aplikasi yang bertujuan untuk lebih memberikan warna pada wajah dengan menonjolkan kelebihan-kelebihan yang ada pada wajah hingga penampilan menjadi lebih cantik. Riasan dekoratif dapat dilakukan dengan mengaplikasikan kosmetika mascara, eye shadow, eye brow pencil, eye liner, bayangan hidung untuk menyempurnakan penampilan wajah (Herni Kusantati, 2008:452).

Tata rias pada seni tari sarana pembantu yang berperan mendukung pertunjukan tari (Atang Supriatna, 2010:109). Tata rias merupakan hal yang sangat penting dalam pertunjukan tari dikarenakan penonton selalu melihat bentuk riasan dari seorang pemain atau penari untuk mengetahui tokoh apakah yang sedang dibawakan dan siapakah yang membawakan.

Tata rias juga diperlukan untuk dapat memunculkan karakter tokoh yang dibawakan, oleh karena itu riasan penari harus sesuai dengan tokoh atau tema tarian yang diperankan. Tata rias terbagi dalam dua macam yaitu rias wajah, rias rambut. Rias wajah bertujuan untuk membuat wajah lebih menarik dan sesuai dengan karakter yang dibawakan. Rias rambut adalah riasan yang dilakukan untuk mengubah bentuk rambut. Rambut ditata supaya lebih rapi dan dapat mendukung rias wajah agar dapat memunculkan karakter yang tepat.

Tata busana adalah segala suatu yang dipakai dari rambut sampai kaki atau dapat dikatakan kostum yang dikenakan penari di atas panggung. Tata busana bertujuan untuk mengubah, memperindah diri dan memunculkan karakter melalui busana yang dipakai.

$\begin{array}{cc}\text { Desa Kedis, } & \text { Kecamatan } \\ \text { Busungbiu yang ada di Kabupaten }\end{array}$ 
Buleleng memiliki banyak kesenian daerah yang diciptakan oleh para leluhur disana salah satunya yaitu tari rejang keraman. Tari Rejang Keraman tertulis dalam lontar Purwagama hasil karya Rsi Markandya pada saat itu beliau menyebarkan Agama Hindu di Bali dan menjadi Bagawanta Putri pada abad XVI. Bahasa yang digunakan dalam penulisan sejarah adalah bahasa sederhana. Sedangkan tari Rejang Keraman yang dipentaskan dalam upacara Ngusaba Agung di Pura Puseh Desa Kedis mengikuti hasil Pesamuhan para Pengelingsir Desa Kedis saat pembentukan Desa Kedis. Tari Rejang Keraman termasuk tari wali yang merupakan tarian sakral yang ditarikan oleh putra dan putri yang baru menginjak dewasa. Tarian ini melambangkan ungkapan rasa syukur dari masyarakat, serta merupakan ungkapan hati dan rasa bhakti terhadap Ida Sang Hyang Widhi Wasa. Tarian ini dipentaskan pada saat Ngusaba Agung yang bertepatan dengan Purnama Kapat yang diperingati tiga tahun sekali, tarian ini dipentaskan secara turun-temurun.

Berdasarkan wawancara dengan kelian adat dan kelian banjar Desa Kedis pada tanggal 14 September 2017 yang menyatakan "Bahwa tata rias wajah pada tari rejang keraman hampir sama dengan tata rias wajah tari rejang dewa perbedaannya hanya pada pemakaian eyeshadow, tari rejang keraman pada jaman dahulu belum menggunakan eyeshadow karena perias belum mengenal istilah eyeshadow. Untuk tata rias wajah putra sama dengan tata rias wajah putri tetapi pada tata rias wajah putra ditambahkan kumis untuk mempertegas kewibawaan laki-laki. Untuk aksesoris kepala yang digunakan tari rejang keraman sangat berbeda dengan aksesoris yang digunakan tari rejang dewa. Pada tari rejang keraman gelungan yang digunakan untuk putri menggunakan gelungan tari janger, dulu aksesoris pada kepalanya menggunakan rambut asli karena pada jaman dulu sebagian besar perempuan mempunyai rambut panjang, dan untuk busananya juga tidak hanya menggunakan kain putih kuning yang biasa digunakan tari rejang dewa, dan untuk penari putra menggunakan gelungan tari baris dan menggunakan busana tari baris."

Menurut Jro Ketut Cakra pada tanggal 18 Oktober 2017 sebagai perias tari rejang keraman mengatakan "Bahwa tata rias wajah tari rejang keraman sangat sederhana karena belum adanya kosmetika yang lengkap seperti sekarang dan untuk mengaplikasikan kosmetik hanya menggunakan tangan. Bedak yang digunakan yaitu bedak tabur yang dicampurkan dengan air, yang sekarang dikenal dengan istilah bedak kocok. Maka dari itu bedak tersebut tidak bisa bertahan lama dan mudah luntur saat terkena air atau keringat. Untuk membuat alis-alisnya digunakan yang dalam bahasa balinya dikenal mangsi berwarna hitam yang dicampur dengan air setelah itu dioleskan pada alis-alis penari yang berfungsi untuk sekedar menghitamkan alis-alis, sedangkan untuk bibir digunakan getah daun jati muda yang dioleskan di bibir agar terlihat merah seperti memakai lipstik, untuk perona pipi digunakan klapklip/manik-manik yang sekarang dikenal dengan nama mute yang berwarna merah dengan cara menempelkan pada pipi kiri dan kanan seperti menggunakan blus on dan untuk penari putranya hanya menggunakan bedak, mangsi sebagai penghitam alis, getah daun jati untuk perona bibir dan ditambahkan kumis dari mangsi, dan pada jaman dahulu hanya ada foto hitam putih sehingga riasan pada tari rejang keraman ini tidak terlihat jelas seperti gambar penari putri di bawah ini. 


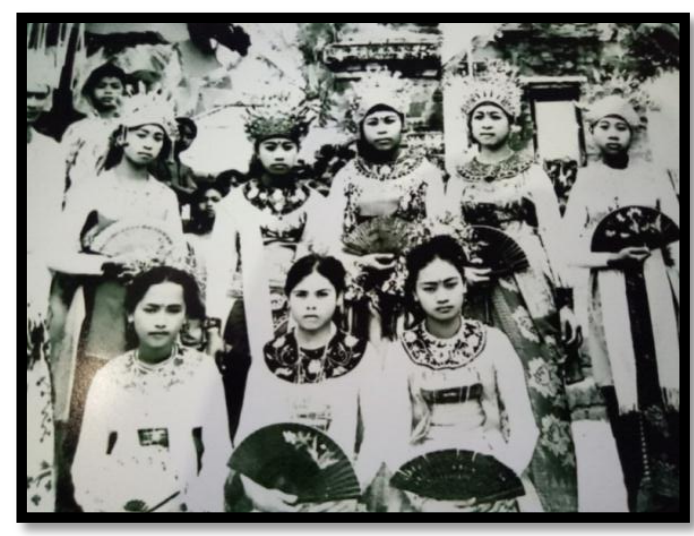

Gambar 1. Tata Rias Tari Rejang

Keraman putri pada Jaman Dulu (Sumber: Dokumentasi Jro Ketut Cakra)

Gelungan yang digunakan untuk riasan kepala tari rejang keraman putri pada jaman dahulu yang terbuat dari seng yang menyerupai gelungan janger dengan hiasan permata yang terbuat dari pecahan kaca dibentuk belah ketupat, dan dilengkapi dengan bunga emas pada bagian belakang kepala. Untuk busana yang digunakan penari rejang keraman putri pada jaman dahulu yaitu menggunakan badong yang berbentuk bulat, busananya menggunakan kebaya berwarna putih yang dibalut dengan menggunakan satagen, angkin prada, tutup dada bludru, selendang dan kamben songket, busana untuk penari putranya menggunakan busana seperti busana tari baris, untuk aksesoris yang digunakan masih memakai kuku panjang palsu yang terbuat dari seng yang berfungsi untuk mempercantik jari-jari penari dan di haruskan untuk menggunakan kalung mas, untuk properti yang digunakan berupa kipas yang terbuat dari bahan kayu cenana.

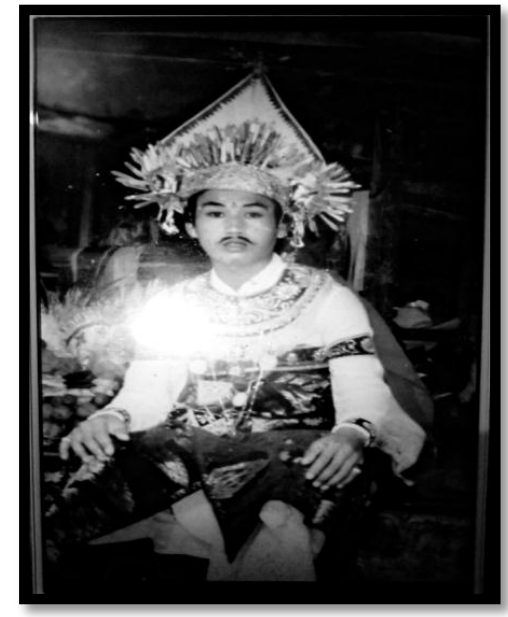

Gambar 1. Tata Rias Tari Rejang Keraman Putra

(Sumber: Dokumentasi Jro Ketut Cakra)

Keunikan dari tata rias tari rejang keraman ini yaitu penari putri memakai kuku panjang palsu yang terbuat dari seng, selain pada kuku keunikan tarian ini adalah harus menggunakan perhiasan berupa kalung emas sebanyak yang dimiliki oleh penari putra dan putri.

Semakin berkembangnya ilmu teknologi dan informasi dalam bidang industri kecantikan akan membawa perubahan pada bahan yang digunakan dalam tata rias termasuk bahan kosmetik yang digunakan pada tari rejang keraman yang mengalami perubahan dengan seiring perkembangan jaman. Di dalam penelitian ini, yang dijadikan pijakan dasar adalah bagaimana tata rias tari rejang keraman pada era modernisasi dilihat dari alat, jenis kosmetika yang digunakan, tata rias wajah, tata rias rambut, dan penataan busana serta aksesoris yang digunakan tari rejang keraman.

Dari pemaparan kelian Adat, kelian Banjar dan Jro Ketut Cakra di Desa Kedis yang bisa memberikan informasi tentang tata rias tari rejang keraman dapat disimpulkan bahwa tata rias tari rejang keraman ini memang berbeda dari tata rias tari rejang pada umumnya dan jenis kosmetik yang digunakan untuk tata rias wajah tari rejang keraman pada jaman dahulu sangatlah sederhana dengan menggunakan bahan-bahan alami. Adapun keunikan yang dimiliki tari rejang keraman ini, yaitu dengan menggunakan kuku panjang palsu, tetapi saat ini kuku 
tersebut sudah tidak digunakan lagi karena sudah tidak ada penerus pembuat kuku palsu tersebut.

Dari perubahan tata rias tari rejang keraman di atas peneliti tertarik untuk melakukan peneliti yang berjudul "Tata Rias Tari Rejang Keraman Pada Era Modernisasi di Desa Kedis Kecamatan Busung Biu Kabupaten Buleleng".

\section{METODE PENELITIAN}

Penelitian ini menggunakan rancangan penelitian kualitatif. Menurut Bogdan dan Taylor (1975:5) penelitian kualitatf adalah prosedur penelitian yang menghasilkan data deskriptif berupa katakata tertulis atau lisan dari orang-orang dan perilaku yang dapat diamati. Lokasi Penelitian ini dilaksanakan di Desa Kedis Kecamatan Busungbiu Kabupaten Buleleng. Dalam penelitian ini peneliti menggunakan metode "snowball sampling" dimana hanya ditentukan jumlah informan kuncinya saja tanpa menentukan jumlah informan pendukung. Sumber informan kunci dalam penelitian ini yaitu Kelian Adat Desa Kedis. dari Kelian Adat mengarahkan ke Kelian Banjar untuk menggali informasi yang sama yaitu tentang tata rias tari rejang keraman setelah itu kelian banjar mengarahkan ke Jro Ketut Cakra sebagai perias tari rejang keraman.Terkait dengan penelitian ini ada beberapa metode yang digunakan yaitu observasi dan wawancara. Adapun objek-objek yang diobservasi dalam penelitian ini antara lain: bahan dan alat tata rias wajah, tata rias rambut, busana, aksesoris dari tata rias tari rejang keraman. Teknik analisis data yang digunakan dalam penelitian tata rias tari Rejang Keraman adalah teknik Deskriptif. analisis data Deskriptif adalah teknik penelitian untuk menghasilkan data berupa kata-kata dan mendeskripsikan kenyataan secara benar tentang tata rias tari Rejang Keraman pada Era Modernisasi di Desa Kedis, Kecamatan Busungbiu, Kabupaten Buleleng.

\section{Hasil dan pembahasan Hasil Penelitian}

1. Alat dan Jenis Kosmetika yang Digunakan pada Tata Rias Wajah dan Rambut Tari Rejang Keraman pada Era Modernisasi di Desa Kedis, Kecamatan Busungnbiu, Kabupaten Buleleng.

a. Alat yang digunakan untuk tata rias wajah dan rambut pada penari putra dan putri.

Dalam merias wajah tari Rejang Keraman pada jaman dahulu hanya menggunakan tangan untuk mengoleskan kosmetik pada wajah penari putra dan putri dan pada jaman yang semakin modern seperti saat ini untuk merias wajah dan rambut Tari Rejang Keraman pada Era Modernisasi sudah sangat lengkap dengan berbagai bentuk yang mempunyai kegunaan masing-masing. Alat yang digunakan untuk merias wajah penari putra dan putri yaitu berbagai bentuk kuas dan bermacam-macam spons. Sedangkan untuk tata rias rambut pada penari putri menggunakan berbagai jenis sisir, karet gelang, jepit rambut hitam, dan harnet. Untuk penari putra hanya menggunakan sisir.

b. Jenis kosmetik yang digunakan untuk tata rias wajah dan rambut pada penari Rejang Keraman putra dan putri.

Pada jaman dahulu jenis kosmetika yang digunakan pada tari Rejang Keraman Putri seperti bedak tabur di campur dengan air, mangsi, getah daun jati, dan klap-klip/mute. Sedangkan jenis kosmetika untuk merias wajah yang digunakan tari Rejang Keraman pada era modernisasi ini yaitu Foundation / alas bedak, Bedak tabur, Bedak padat, Eye shadow, Blush on, Pensil alis hitam, Eyeliner atas, Eyeliner pensil, Lipstick, Mascara, Bulu mata palsu, Lem bulu mata. Dan jenis kosmetika yang digunakan pada jaman dahulu untuk penari putra menggunakan kosmetik seperti bedak tabur yang sudah dicampur dengan air, mangsi, yang terakhir menggunakan getah daun jati. Sedangkan jenis kosmetik yang digunakan penari putra pada era modernisasi ini yaitu sama dengan jenis kosmetika yang digunakan pada penari putri kecuali menggunakan bulu mata 
palsu. Pada tata rias rambut penari putra dan putri hanya menggunakan jenis kosmetika seperti Hair spray.

2. Tata Rias Wajah dan Rambut Tari Rejang Keraman pada Era Modernisasi di Desa Kedis, Kecamatan Busungbiu, Kabupaten Buleleng.

a. Tata rias wajah tari Rejang Keraman pada era modernisasi.

Untuk tata rias wajah putri hal pertama yang dilakukan yaitu penggunaan alas bedak, penggunaan bedak tabur, penggunaan bedak padat, pemberian eyeshadow, pemberian nose shadow. Pemberian eyeliner pencil, pemasangan bulu mata palsu, membentuk alis, pemberian eyeliner cair, pemberian blush on, pemberian lipstick, dan yang terakhir membuat gecek merah.

Untuk tata rias wajah putra dimulai dari penggunaan alas bedak, penggunaan bedak tabur, penggunaan bedak padat, pemberian eyeshadow, pemberian eyeliner cair, membentuk alis, pemberian nose shadow, pemberian blush on, pemberian eyeliner pensil, membentuk caping, pemberian cundang dan hiasan, pemberian lipstick, dan yang terakhir pemberian kumis palsu.

b. Tata Rias Rambut Tari Rejang Keraman pada Era Modernisasi

Untuk putri dimulai dari mengikat rambut, menggulung rambut, pemasangan antol, pemasangan gelung, yang terakhir pemasangan bunga emas dan bunga palsu. Dan untuk putra hanya menggunakan gelung tari baris dan diperkuat dengan menggunakan jepit hitam agar tidak lepas pada saat menari.

3. Penataan Busana dan Aksesoris Tari Rejang Keraman pada Era Modernisasi di Desa Kedis, Kecamatan Busungbiu, Kabupaten Buleleng.

Tatanan busana dan aksesoris tari rejang keraman pada era modernisasi untuk putri dimulai dari pemakaian kebaya, pemakaian kamben songket, pemakaian angkin prada, pemasangan selendang, pemasangan tutup dada bludru, pemasangan ampok-ampok, dan yang terakgir yaitu penggunaan aksesoris seperti gelang kana, kalung emas, dan subeng cerorot.

Untuk putra tatanan Busana dan Aksesoris dimulai dengan pemakaian baju putih berlengan panjang dan celana putih panjang, penggunaan stiwel dan gelang kana baris, pemakaian kancut putih, penggunaan ampok-ampok tari baris, penggunaan kamben songket, penggunaan semayut, pemasangan busana tari baris yang terdiri dari (angkep pala, lamak, dan awir), penggunaan badong, dan yang terakhir pemasangan kris.

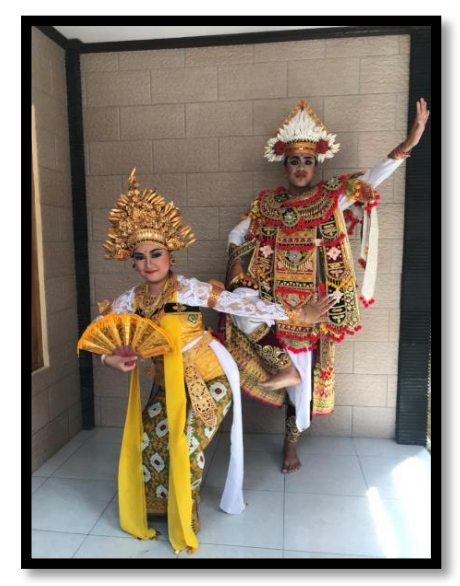

Gambar 3. Hasil Akhir Tari Rejang Keraman Putra dan Putri Pada Era Modernisasi

(Sumber : Dokumentasi Pribadi)

\section{PEMBAHASAN}

1. Alat dan Jenis Kosmetika yang. digunakan pada Tata Rias Wajah dan Rambut Tari Rejang Keraman pada Era Modernisasi di Desa Kedis, Kecamatan Busungnbiu, Kabupaten Buleleng.

Pada jaman dahulu alat yang digunakan untuk merias tari Rejang Keraman sangatlah sederhana. Pada saat merias tari penata rias tidak menggunakan alat untuk mengaplikasikan kosmetik yang digunakan, mereka hanya menggunakan jari tangan untuk mengoleskan kosmetik pada wajah penari, karena pada saat itu belum ada alat yang seperti sekarang. Untuk jenis 
kosmetika yang digunakan pada jaman dahulu juga sangat sederhana yang terbuat dari bahan alami seperti menggunakan bahan yang dalam bahasa bali dikenal dengan mangsi untuk membuat alis dan kumis palsu pada penari putra, getah daun jati untuk perona bibir, bedak tabur, klap-klip yang digunakan sebagai pemerona pipi dan untuk aksesoris pada rambut menggunakan gelungan yang tebuat dari seng yang menyerupai gelungan janger dan untuk penari putra hanya menggunakan gelungan terbuat dari ental yang menyerupai gelung tari baris. Dengan berkembangnya jaman yang semakin modern tari rejang keraman sudah menggunakan alat tata rias wajah dan rambut yang sudah terbuat dari pabrik seperti spon alas bedak, spon bedak tabur, spon bedak padat, powder brush / kuas bedak, blush brush / kuas blush on, fan brush / kuas sapu, angled eye shadow / kuas kerung, large eye shadow brush / kuas eye shadow besar, medium eye shadow brush / kuas eye shadow sedang, small eye shadow brush / kuas eye shadow kecil, eye liner brush / kuas eye liner, sponge aplikator / spon eyeshadow, lash fiber / sikat bulu mata, eye shadow comb / sisir alis, lip brush / kuas bibir, sisir sasak, sisir penghalus, jepit rambut hitam, ikat rambut, harnet. Dengan alat-alat yang digunakan pada saat ini membuat riasan wajah dan rambut penari rejang keraman menjadi lebih terlihat indah dan ditambah lagi dengan jenis kosmetika yang digunakan pada era modernisasi ini seperti milk cleansing/pembersih wajah, pelembab, foundation/alas bedak, bedak tabur, bedak padat, eye shadow, nose shadow, blush on, pensil alis hitam, eyeliner cair, eyeliner pensil, lipstick, mascara, bulu mata palsu, lem bulu mata, dan hair spray membuat tata rias wajah dan rambut terlihat lebih rapi, dan sempurna.

Dari hasil penelitian di atas dapat dinyatakan bahwa alat yang digunakan pada tata rias tari Rejang Keraman di Desa Kedis sudah mengalami perubahan dari yang dulunya hanya mengunakan tangan untuk mengaplikasikan kosmetik sekarang sudah menggunakan berbagai macam bentuk kuas yang lengkap. Selain perubahan dengan alat, dengan berkembangnya jaman yang semakin modern jenis kosmetika juga sudah mengalami perubahan. Jenis kosmetika yang dulunya hanya menggunakan bahan alami dan mudah di dapat sekarang sudah menggunakan kosmetika yang berbagai macam yang terbuat dari pabrik dan hasilnya juga lebih terlihat sempurna dari riasan yang terdahulu.

Hal ini sependapat dengan Widjojo Nitisastro (2011) yang menyatakan Modernisasi adalah suatu transformasi total dan kehidupan bersama yang tradisional atau pramodern dalam arti teknologi serta organisasi sosial, ke arah pola-pola ekonomis. Perubahan tersebut seperti alat, jenis kosmetika, dan aksesoris yang digunakan pada tari rejang keraman pada jaman dahulu hingga sekarang sudah semakin berkembang dan menjadi lebih praktis.

2. Tata Rias Wajah dan Tata Rias Rambut Tari Rejang Keraman pada Era Modernisasi di Desa Kedis, Kecamatan Busungbiu, Kabupaten Buleleng.

Tata rias wajah dan rambut tari rejang keraman Desa Kedis dulunya sangatlah sederhana karena belum adanya kosmetik, tetapi dengan perkembangan jaman yang semakin modern seperti saat ini, tata rias wajah dan rambut tari rejang keraman ini sudah menggunakan kosmetik dan alat yang lengkap untuk merias wajah dan rambut penari. Perbedaan tata rias wajah tari rejang keraman putri pada jaman dulu dengan sekarang yaitu pada jaman dulu langkah awal dalam merias wajah dimulai dengan menggunakan bedak tabur yang dicampur dengan air yang berfungsi sebagai alas bedak, setelah itu membentuk alis yang menggunakan mangsi yang dicampur dengan air, dilanjutkan dengan penggunaan klapklip/manik-manik yang sekarang dikenal dengan mute pada pipi yang berfungsi sebagai perona pipi, selanjutnya penggunaan lipstik dari bahan getah daun jati, dan yang terakhir pemberian gecek pada tengah-tengah pangkal alis 
menggunakan getah daun jati yang melambangkan pancaran dari lda Sang Hyang Widhi. Sedangkan pada tata rias wajah tari rejang keraman sekarang dimulai dengan penggunaan alas bedak, penggunaan bedak tabur, penggunaan bedak padat, pemberian eye shadow (kuning emas, coklat, cream, dan hitam), pemberian nose shadow, membentuk alis dengan pensil alis hitam, pemasangan bulu mata palsu yang bertujuan untuk memberi kesan pada bulu mata asli agar telihat lebih tebal dan lentik, pemebrian eyeliner cair, pemberian eyeliner pensil, pemberian blush on, pemberian lipstik, dan membuat gecek merah pada tengahtengah pangkal alis menggunakan lipstik berwarna merah. Selain tata rias wajah tari rejang keraman putri yang mengalami perkembangan, tata rias wajah penari putra juga mengalami perubahan. Pada jaman dulu tata rias wajah tari rejang keraman putra sangatlah sederhana hanya menggunakan bedak, alis-alis dan kumis dari mangsi yang melambangkan kewibawaan seorang laki-laki yang mulai menginjak dewasa, dan yang terakhir membentuk cundang yang meruncing ke atas pada tengah-tengah pangkal alis yang menggunakan mangsi sebagai simbol rasa bakti terhadap Ida Sang Hyang Widhi. Sedangkan tata rias wajah penari putra pada saat ini sudah sangat lengkap seperti tata rias tari baris. Tata rias wajah penari putra sekarang dimulai dengan penggunaan alas bedak, penggunaan bedak tabur, penggunaan bedak padat, pemakaian eye shadow dengan warna-warna yang terang (biru, merah, kuning), pemberian nose shadow, membentuk alis menggunakan pensil alis hitam, pemberian eyeliner cair dan eyeliner pensil, pemberian blush on, pemberian lipstik, di tambah dengan pemberian caping menggunakan pensil alis hitam yang bertujuan untuk mempertegas perwatakan sebagai penari putra, selanjutnya pemberian kumis dengan pensil alis hitam, dan yang terakhir yaitu membentuk cundang pada tengah-tengah pangkal alis dan di tambah pemberian hiasan pada pelipis kiri kanan yang menggunakan pasta gigi berwarna putih. Dari perbedaan tata rias wajah tari rejang keraman putra dan putri pada jaman dahulu dengan sekarang sangat terlihat berbeda, tetapi dari perbedaan itu ada beberapa tata rias wajah yang memang harus tetap digunakan dari jaman dulu hingga sekarang yang mempunyai makna tersendiri yaitu seperti gecek merah pada tata rias wajah penari putri, dan penggunaan cundang serta pemberian kumis pada penari putra. Maka dari itu dari hasil wawancara dengan penata rias tari rejang keraman Desa Kedis mengatakan bahwa tata rias yang digunakan tari rejang keraman pada era modernisasi adalah tata rias yang menunjang penampilan para penari lebih terlihat menarik dan menggunakan riasan yang memang untuk pementasan tari yang menggunakan teknik-teknik dalam merias tari bali.

Tata rias rambut pada tari rejang keraman untuk putrinya pada jaman dulu menggunakan rambut asli, karena pada jaman dulu masih banyak wanita yang masih mempunyai rambut panjang dan pada jaman dahulu penari putri menggunakan gelungan yang terbuat dari seng yang menyerupai gelung tari janger, dengan berkembangnya jaman seperti saat ini wanita sudah jarang yang mempunyai rambut panjang, maka dari itu penata rias menggunakan antol sebagai pengganti rambut asli dan gelungan yang digunakan juga mengalami perubahan, gelungan yang digunakan saat ini yaitu gelungan tari sekar jagat karena sudah tidak ada penerus yang bisa membuat gelungan yang seperti dulu, selain itu gelung tari sekar jagat lebih praktis untuk digunakan. Tata rias rambut penari putri dimulai dengan mengikat semua rambut dengan karet dan harnet pada atas kepala di belakang ubun-ubun rambut, selanjutnya pemakaian antol dengan menggunakan jepit hitam, dilanjutkan dengan penggunaan gelung tari sekar jagat, selanjutnya pemasangan bunga emas dan bunga palsu. Untuk tata rias rambut penari putra hanya menggunakan gelung tari baris. Pada jaman dulu gelungan yang digunakan penari putra yaitu gelungan yang terbuat dari janur ental dan dihiasi yang menyerupai bentuk gelungan tari baris dan pada saat ini 
penari putra sudah menggunakan gelung tari baris yang sebenernya.

Hal ini sependapat dengan Rusliana (1982:12) Make up / tata rias adalah membuat garis-garis di wajah sesuai dengan konsep garapan. Tata rias dalam tari sangat berbeda dengan tata rias sehari-hari, karena riasan disini berfungsi untuk membantu ekspresi ataupun perwujudan watak si penari.

3. Penataan Busana dan Aksesoris Tari Rejang Keraman pada Era Modernisasi di Desa Kedis, Kecamatan Busungbiu, Kabupaten Buleleng

Penataan busana dan aksesoris tari rejang keraman sangat dibutuhkan, ini diakibatkan karena pementasan tari rejang keraman sangat disakralkan oleh masyarakat Desa Kedis. Busana yang digunakan tari rejang keraman pada era modernisasi ini tidak jauh berbeda dengan busana yang digunakan pada jaman dahulu. Tari rejang keraman putri pada jaman dahulu dan yang sekarang menggunakan kebaya berwarna putih dengan bahan yang berbeda, kalau dulu semua penari menggunakan kebaya yang sama terbuat dari kain katun, sedangkan kebaya yang digunakan sekarang sudah berbeda-beda sesuai kebaya apa yang ingin digunakan penari asalkan kebaya yang digunakan tidak terlalu terbuka, setelah menggunakan kebaya dilanjutkan dengan menggunakan kamben songket, menggunakan stagen untuk memperkuat kamben agar tidak lepas, Stagen atau penutup pinggang pada jaman dahulu yang digunakan penari dari pinggang hingga ke dada adalah sabuk tradisional Bali, sedangkan stagen yang digunakan sekarang sudah lebih praktis dan bentuknyapun berbeda, setelah menggunakan stagen selanjutnya menggunakan angkin prada, setelah itu selendang putih kuning, Warna-warna tersebut memiliki arti tersendiri. Warna putih menyimbolkan dewa Iswara, yaitu mempunyai makna kesucian dan kebenaran. Warna kuning merupakan simbol dari Dewa Mahadewa yang mempunyai makna kebahagiaan, setelah itu penggunaan tutup dada bludru, ampokampok, dan badong. Badong yang digunakan pada jaman dahulu menggunakan badong yang berbentuk bulat, sedangkan yang sekarang penari putri menggunakn badong yang berbentuk lancip sesuai dengan badong tari sekar jagat. setelah itu dilanjutkan dengan pemasangan subeng cerorot, gelang kana, dan kalung emas. Pada jaman dahulu penggunaan kalung emas ini mempunyai arti yaitu memperlihatkan miskin dan kayanya warga di Desa Kedis, karena penari diharuskan memakai kalung emas sebanyak yang dimiliki penari.

Pada penataan busana untuk penari putra pada jaman dahulu dan sekarang sudah mengalami perubahan. Busana penari putra pada jaman dahulu hanya menggunakan baju putih berlengan panjang, celana putih panjang, stiwel yang digunakan pada pergelangan kaki, setelah itu menggunakan kancut berwarna putih dan menggunakan kamben songket yang dipasangkan pada bagian dada penari, selanjutnya digunakan sabuk bludru pada dada untuk memperkuat kamben agar tidak lepas, setelah itu pemasangan badong, gelang kana, dan kalung emas. Sedangkan penataan busana saat ini sudah menggunakan tatanan busana penari baris dengan lengkap yaitu menggunakan baju polos putih berlengan panjang, celana putih panjang, stiwel, kancut putih, stagen, kamben songket, ampok-ampok tari baris, semayut, badong, busana tari baris yang terdiri dari angkep pala, lamak, dan awir, dilengkapi dengan penggunaan gelang kana tari baris dan kris.

Hal ini sependapat dengan Chodiyah dan Mamdy (1982:8) yang menjelaskan tentang tata busana haruslah sesuai dengan konsep garapan baik desain busana maupun warnanya, pada prinsipnya tata busana sama dengan tata rias yaitu membantu menghidupkan perwatakan penari yang dimaksud adalah semua kebutuhan sandang yang dikenakan pada tubuh penari di atas pentas yang sesuai dengan peranan yang ditawarkan. Seorang penata busana juga harus memperhitungkan efek lampu serta komposisi warna yang disusun, demikian juga kemungkinan-kemungkinan terhadap 
keleluasan penari sesuai dengan watak yang diperankan.

\section{SIMPULAN DAN SARAN Simpulan}

\author{
Berdasarkan hasil penelitian yang \\ dilakukan maka dapat disimpulkan \\ sebagai berikut.
}

1. Alat, Jenis Kosmetika, dan Aksesoris yang Digunakan pada Tata Rias Tari Rejang Keraman pada Era Modernisasi di Desa Kedis.

Alat dan jenis kosmetika yang digunakan pada tari rejang keraman pada era modernisasi sudah sangat lengkap sehingga tata rias tari rejang keraman sekarang terlihat lebih sempurna dibandingkan dengan tata rias pada jaman dahulu. Karena pada jaman dahulu untuk merias tari rejang keraman belum menggunakan alat dan kosmetika yang seperti sekarang, dulu hanya menggunakan tangan untuk mengoleskan kosmetik, dan kosmetik yang digunakanpun masih terbuat dari bahan alami, lain dengan sekarang yang sudah menggunakan berbagai macam alat dan kosmetika seperti berbagai bentuk kuas dan kosmetika yang sudah tebuat dari pabrik dengan bahan-bahan buatan. Selain perubahan pada alat dan kosmetika, aksesoris yang digunakan pada tata rias rambut tari rejang keraman juga mengalami perubahan seperti gelungan yang digunakan penari putri yang dulunya menggunakan gelungan yang terbuat dari seng tetapi sekarang sudah menggunakan gelung tari sekar jagat yang lebih praktis untuk digunakan, dan untuk penari putranya dulu menggunakan gelung yang tebuat dari ental yang menyerupai gelung tari baris dan sekarang sudah menggunakan gelung tari baris yang asli.

\section{Tata Rias wajah dan Rambut Tari Rejang Keraman Pada Era} Modernisasi di Desa Kedis.

Tata rias wajah yang digunakan tari rejang keraman pada era modernisasi mengguakan tata rias yang menunjang penampilan penari lebih terlihat sempurna dengan memperhatikan tekstur ketebalan dalam tata rias tari Bali. Tata rias rambut tari rejang keraman putri tidaklah begitu sulit, seperti mengikat rambut pada atas kepala dan digulung rapi di belakang ubun-ubun dengan menggunakan karet dan harnet, setelah itu memasangkan antol pada rambut yang digulung, lalu memasang gelung tari sekar jagat dan memberikan hiasan seperti bungan emas dan bunga mawar palsu pada bagian belakang. Pada tat arias rambut penari putra hanya menggunakan gelung tari baris.

\section{Penataan Busana dan Aksesoris Tari} Rejang Keraman pada Era Modernisasi di Desa Kedis.

Penataan busana tari rejang keraman putri pada era modernisasi menggunakan kebaya putih, kamben songket, angkin prada, selendang putih kuning, tutup dada bludru, ampok-ampok, dan badong. Pada penari putranya penataan busana menggunakan baju dan selana panjang berwarna putih, stiwel, gelang kana baris, kancut putih, ampok-ampok tari baris, kamben songket, semayut, busana tari baris (angkep pala, lamak,awir), dan badong.

\section{Saran}

Berdasarkan pembahasan hasil penelitian dan simpulan, maka dapat diajukan saran sebagai berikut:

1. Agar masyarakat di Desa Kedis yang tua maupun yang masih muda mengetahui bagaimana perkembangan atau perubahan tata rias tari Rejang Keraman pada jaman dahulu hingga saat ini. Karena tarian ini sangat disakralkan dan berasal dari Desa Kedis itu sendiri.

2. Agar masyarakat Desa Kedis bisa meneruskan keunikan dan ciri khas dari tata rias tari Rejang Keraman seperti gelungan yang digunakan dan kuku palsu yang terbuat dari seng pada jaman dahulu yang hilang karena tidak ada penerus dalam pembuatannya.

\section{DAFTAR RUJUKAN}


Jurnal Bosaparis: Pendidikan Kesejahteraan Keluarga

Volume 9, Nomor 2, Juli 2018

Atang Supriatna, (2010). Pendidikan Seni

Tari. Jakarta : Pusat Pembukuan, Kementrian Pendidikan Nasional.

Bogdan dan Taylor, 1975 dalam J. Moleong, Lexy. 1989.Metodologi Penelitian Kualitatif. Bandung: Remadja Karya.

Chodiyah \& Wisri A. Mamdy. (1982), Disain Busana, Jakarta, Dikmenjur,Depdikbud.

Herni Kusantati, dkk, (2008). Tata Kecantikan Kulit Jilid 3, Jakarta :
Direktorat Pembinaan Sekolah Menengah Kejuruan.

Rusliana, (1982). Pendidikan Seni Tari Untuk SMTA. Bandung : Angkasa

Widjojo Nitisastro. Modernisasi. Diakses pada 27 September 2011 dari https://socius3.wordpress.com/tag/w idjojo-nitisastro.html

Yudabakti, I Made (2007). Filsafat Seni Sakral dalam Kebudayaan Bali, Surabaya : Paramita. 